\title{
Using an Integrated System Approach to Manage Conflict
}

\author{
Chanique Williams \\ Prairie View A\&M University \\ Eunrekea Moore \\ Prairie View A\&M University \\ Corey Williams \\ Prairie View A\&M University \\ Richard Jones \\ Prairie View A\&M University \\ Reginald L. Bell \\ Prairie View A \& M University \\ Reginald Holloway \\ Prairie View A \& M University
}

We examined the current literature to determine if workplace conflict could be resolved by using an integrated conflict management system approach. This paper discusses ways to resolve conflict between persons. Human values differ on many levels of organizational culture; therefore, workplace conflict is inevitable, and it is often unavoidable in toxic workplaces. We uncovered numerous managerial communication strategies that can be useful to resolve workplace conflict. The current literature suggests that effective interpersonal communication plays an important role in conflict resolution. Several communication strategies were found to adequately address the main causes of conflict between people. We recommend 8 steps in 3 stages (SIP, DINE, and DANCE) necessary to resolve workplace conflicts, regardless of the line of work of the manager.

Keywords: Conflict, Integrated Approach, Systems, Organization, Culture, Managerial Communication

\section{CONFLICT MANAGEMENT IN TOXIC WORKPLACES}

General abrasive behavior between work groups involve aggressive people who seem to have no filter about what they say or how they say it. Employees who feel threatened within their current roles tend to be more abrasive, engage in incivility, and resort to workplace bullying (Branch, et al 2004; Fox, \& 
Stallworth, 2009; Glambek, Skogstad, \& Einarsen, 2018; Shane-Joyce \& Bell, 2010). Abrasive managers at any level can inflict deep wounds and cause intense suffering within their employee groups. Laura Crawshaw has argued that the theory of natural selection in our current workplace has been adopted. She argues further that people live in a society that welcomes the survival of the fittest mindset which has fostered abrasive behavior (Crawshaw, 2010). However, conflicts and disputes do not always have to result in destructive courses of action; they can also lead to growth and productivity for those involved (Moore, 1986).

The term toxic is defined as "containing or being poisonous material especially when capable of causing death or serious debilitation" (Merriam-Webster). Kristen Fuller has stated that there are red flags associated with toxic behaviors: lying, outright refusal to deal with conflict, talking poorly about others, and being manipulative (Fuller, 2017). One study found that sick calls resulting from bullying can cost a company $\$ 30,000$ to $\$ 100,000$ annually (Glambek, Skogstad, \& Einarsen, 2018). The correct way to address toxic behavior is to first address the behavior directly (McCarthy, Sheehan, \& Kearns, 1995). A manager must remain diplomatic, neutral, and polite toward a toxic employee; this will help to defuse any problem behavior. Notwithstanding, managers must be bold enough to care about the employees' whole life and understand that their "toxicity" is reflective of something deeper going on.

There are five common causes of workplace conflict conversations: 1) scapegoating, 2) lack of accountability, 3) confusing stories, 4) acting selfishly, and 5) not taking the respective team into consideration (Knight, 2015). Scapegoating is extremely dangerous because it breaks down trust and also creates a hostile workplace. When the manager is also an accountable leader accountability prevents scapegoating. Lack of accountability, and silence go hand and hand with each other. If there is no accountability for the issues within the workplace, it could damage the cohesiveness of the team. Confusing stories with facts as focus opens the door for hearsay and gossip as opposed to a focus on reality. The main cause for a conflict conversation would be acting selfishly and not taking the respective team into consideration when decisions are being made (Overton, 2013).

Conflict conversations can be a challenge to a management group experiencing conflict. In order to conduct difficult conversations, managers need to understand what others feel and think who are not expressing how they feel or think (Stone, Patton, \& Heen, 2010). Each conflict conversation should be broken into three investigatory conversations: "What happened?" "How am I feeling?" and "What is the conflict saying about me?" In order to engage in effective conflict conversations, managers must be open to understanding employees' stories. Conflict conversations are extremely beneficial to a team having conflicts. When conflict is successfully addressed, multiple benefits accrue to the organization and individuals. If a plan with timelines is not designed and implemented, the employee's behavior will typically change for a period of time but then slip back into old patterns. The risk of ignoring conflict is costly for an organization, even in situations of different levels of authority or power (Overton, 2013).

Rian Thomas argues in Conflict Management: A Methodology for Addressing the Cost of Conflict in the Workplace that there are three main components to conflict management: training, neutral third-party interventions, and a supportive infrastructure (Thomas, 2002). The literature suggests companies are losing money every day due to unforeseen workplace conflict issues. One study from 2008 found that US employees were spending 2.8 hours per week dealing with conflict, an amount approximately $\$ 359$ billion in paid hours, the equivalent of 385 million days of lost productivity (Lawler, 2010). There is a study from 2012 which found the Canadian economy lost an estimated \$16.1 billion due to unresolved conflict (Howatt HR Consulting, 2015).

For decades organizations have operated on a case-by-case basis when they are implementing conflict resolution strategies. If one strategy failed, a different strategy was chosen, often at random with no rhyme or reason. It was unpredictable whether conflict in the workplace would be resolved. If a popular or senior level employee or a manager with tenure had a conflict with another, often the organization would cave to their demands by accommodating the preferred strategy (Bell \& Martin, 2014). Organizations would go-along to get-along and try keeping the peace short-term. But, this would have long-term effects with team morale. Others simply might call it the compromising strategy where supervisor and employee might both give a little resulting in a zero-sum gain. But, often it never ended 
this way (Dontigney, 2018). The idea was for each side to collaborate where both sides could work together for the greater good of the organization, but usually ended up competing against one another. In other words, supervisors did not care how employees felt, and would resort to coercive action to get the job done or assigned task completed.

\section{Levels of Workplace Conflict}

Conflict is "the process by which two or more parties are engaged in a disagreement" (Shonk, 2018). Conflict can also be a choice between or among options, favorable or unfavorable (Bell, 2013; Bell \& Martin, 2019a). There are several triggers that cause conflicts to occur. Conflict in the workplace can have both positive and negative effects on business operations, individual productivity, and human efficiencies. Moreover, conflict is not always negative. Sometimes good conflict challenges the status quo. Conflict management suggests that different people perceive things differently. Thus, conflict is not always bad. The main drivers of conflict are perceived differences, which are plenty in diverse modern workplaces (Corkindale, 2007). Unfortunately, intercultural workplaces make conflict unavoidable because of the wide array of differences in human cultures. Causes of conflict include a lack of understanding, personality clashes, competition, authority issues, lack of cooperation, low performance, perceived employee value, organizational openness and diversity, indecision on the part of management among selecting options, or goal differences (Aula \& Siira, 2010; Beckwith, 2016; Bell, 2013).

Workplace conflict is broadly generalized into four main categories: 1) environment, 2) individual, 3) organizational, and 4) workplace (Beckwith, 2016). Under the environmental category some of the sources of conflict are economic, legal, demographic, and political/social. Within the individual bucket the sources are personality, stability, and health. From an organizational standpoint the sources are profitability, productivity, leadership, governance, structure, and ownership. From the workplace bucket comes work, technology, workforce, and working conditions. When attempting to resolve conflict, it is important to use a practical approach, described in detail in the book "Resolving Conflict: A Practical Approach" (Tillett, 1991); which focuses on practical skills and processes, including conflict analysis, collaborative problem solving, mediation, negotiation and arbitration. Conflict in the workplace occurs often and must be resolved (whether good or bad) so there is no degenerative effect on the business. The manager resolving a conflict situation must possess the necessary soft skills to resolve the conflict in a manner that all team members are comfortable with the resolution.

\section{Managerial Communication as a Soft Skill}

Soft skills are essential for managers when communicating with others. Being an effective communicator is not inherent, but must be practiced daily (Harper, 2012). When managers are in tune with their emotional intelligence (e.g. positive attitude, organizing, critical thinking), they are more effective overall because they can sustain interpersonal relationships due to self-awareness. Supervisors would delegate a task, and would not care how it was done, so long it was completed by the delivery date. When leaders are empathetic with subordinates, it helps build rapport and trust within the ranks, especially on the frontline or technical core of the organization (Ahmed, et al 2010; Baughman, et al 2007; Bell, 2012). Employees want to work for managers who have an open mind, think outside the box, understand different perspectives, and listen before responding (Harper, 2012) as well as giving feedback regardless of the manager's gender (Roebuck, Bell, \& Hanscom, 2016).

Managerial communication is critical when conflict conversations are needed. Managers must figure out how to alleviate feelings of inequity among their subordinates (Bell, 2011a) including misconceptions of inequity in wages between genders (Bell, Sutanto, Baldwin, \& Holloway, 2014) while also solving conflicts associated with incivility among team members (Shane-Joyce \& Bell, 2010). Managers also focus on "Team Management by Objectives" as a strategy to assist teams through the five stages of team development from the perspective of performance at each stage (Fulk, Bell \& Bodie, 2011). Managing abrasive behaviors requires interpersonal communication skills as a scientific management approach to personal productivity (Bell \& Martin, 2012). Strategies for employee retention is especially critical when the soft skill of communication can mean retaining or losing key employees at junctures where human 
capital is essential for accomplishing organizational goals (Cloutier, et al 2015). For example, intercultural difference in listening is an important topic for intercultural management practices in global environments and diverse workplaces. Cultures appear to influence how managers listen and what managers listen to (Roebuck, Bell, Raina, \& Lee, 2015; Roebuck, Bell, Raina, \& Lee, 2016). Managerial delegation of authority is also a soft skill that if done correctly can alleviate potential workplace conflict (Bell \& Bodie, 2012). In some cases, diversity is an organizational imposition that requires communication directives from top to bottom, where management takes a lead-by-example role on illustrating to all constituents the importance of multicultural values (Thibeaux, et al 2006). Managerial communication has been defined as "the upward, downward, and horizontal sending and receiving messages between a source and a receiver, where information is exchanged and meaning is shared, for the purpose of achieving a managerial goal" (Bell \& Martin, 2008). This definition is germane to conflict conversations, as conflicts can occur across all levels of the organization and all lines of management.

Communication as a soft skill can be viewed as the most important skill one can possess (Bell, 2010a; Bell, 2010b: Bell, 2011b; Bell, 2011c; Doyle, 2018). It is a process that is continuous in time. Communication is an interaction between people and used to convey thoughts, ideas, desires, and emotions. Communication comes in plenty of different forms: verbal, written, visual, or non-verbal (body language or gestures). Effective communication is the ability to express yourself in a way that things are understood. A good communicator is not only known for verbal communication, but can also read behavior, body language, and adapt to different situations.

Emotional intelligence is used to refer to a group of inner qualities that make up an employee. Such as a positive attitude, communication skills, planning and organizing, critical thinking, and interpersonal skills (Nguyen, et al 2019). It can also be viewed as the measure of an individual's abilities to recognize and manage his or her emotions, and the emotions of other people. People with higher emotional intelligence seem to find it easy to form and maintain interpersonal relationships and to fit in to group situations. They are also more aware of their own mental state, which helps with managing stress and not becoming depressed. People who are emotionally intelligent possess personal skills like self-awareness, self-regulation, and motivation. They also have social skills and empathy for others (Goleman, 2006).

Empathy is also known as a soft skill. It is a very significant skill in a workplace setting, being able to see things from another person's perspective and sympathize with someone's emotions go a long way (Bell, 2010a). There are five key points to using empathy in the workplace. Conflict conversation to be effective must be goal oriented. The first is to see things from the other person's point of view. Second, try to validate the other party's perspective. Once you see how they came to the perspective they have, acknowledge it. Third, self-regulate your attitude towards the situation. Without an open mind there can be no room for empathy. Fourth, try listening to understand as opposed to listening to respond. Once a person feels that you genuinely are listening to understand, they will most likely feel comfortable enough to listen and open up. Lastly, place yourself in someone else's shoes and ask yourself: what would that person do.

Creative problem solving when dealing with workplace conflict is also a skill that comes in handy. Problem solving is what we do in everyday life and the same process can be applied to the workplace. There are also steps to follow when using the creative problem solving skill. First, identify the issue, remember different people may view the issues in a different way. Second, try understanding everyone's interest. The best solution will be the one that satisfies everyone's interest. Third, list all possible options to solve the problem, this is where the creative juices start to flow. Fourth, evaluate which may be the best. Discuss the pros and cons of each solution. Fifth, decide on which option or options work best. Sixth, document the decision. Putting ideas on paper help you work your way through it. Lastly, come to an agreement on how progress shall be monitored and evaluated.

\section{STRATEGIES FOR MANAGING CONFLICT}

Thus, conflict management styles can be categorized as avoidance, distributive, and integrative as described in Managerial Communication for Organizational Development (Bell \& Martin, 2019a). 
Avoidance involves minimizing or ignoring conflict all together, distributive is confrontational and generally one sided, and integrative relies on cooperation for a shared solution. Within those categories falls the different strategies used when dealing with conflict. These strategies are accommodation, avoidance, collaboration, compromise, and competition (Dontigney, 2018).

The accommodation strategy is the act of awarding the opposition with whatever they demand. This is usually put into practice when one side just wants to keep the peace, and keep things moving along. If this is the primary strategy of a company, it is possible that resentment from management could form.

The avoidance strategy attempts to ignore the situation in hopes that it will just go away. The person who avoids conflict is usually in a position of low power and does not have many options to deal with the conflict. This can lead to bigger problems down the line between employees and management. This might seem to fix the problem in the short term but could build resentment from the employees.

The collaboration strategy is the act of including different people from both parties to come together and create what is known as a "win-win" for both parties. This way both parties walk away satisfied with the outcome and take solace in knowing they were a part of the solution. For this to work both parties must be able to remain calm and focus on nothing but the issues at hand. Collaboration is the process in which both sides work together to find a solution to each other's needs. If done correctly, it could build a strong committed bond from both parties.

The compromise strategy is a common solution used to come to terms in negotiation and mediation processes. Although people might agree on the terms of a deal, it may not resolve the underlying conflict. When compromising on a solution, the art of giving up some things that may be important to you to gain other things, and the opposition in turn are essentially doing the same thing. The tricky part is understanding what exactly is important to the other side, so one can effectively negotiate. When heading into a compromise both parties must be cognizant of the fact that it is very likely they will leave with some, but not all of what they requests. Compromise usually works best when both parties enter the situation with multiple acceptable outcomes.

The competition strategy is used as a last resort when dealing with workplace conflict. This option involves no compromise, collaboration, or any type of working together. It is strictly win at all cost and the other side loses. Winning the conflict is the only concern of the game. This is a strategy used when there needs to be a quick decision, or no hope of reaching an agreement is expected. This strategy could end up with many people feeling resentful and looking elsewhere for employment.

\section{Integrated Conflict Management System}

A growing phenomenon called the "integrated conflict management system," (ICMS) represents a comprehensive, systems approach to the prevention, management and resolution of conflict in the workplace (Conbere, 2001; Liberman, Levy, \& Segal, 2009; Lynch, 2001; Lynch, 2003). The integrated management system was never designed for companies to add techniques with established policies, but to overall the corporate mindset of how companies responded and resolved conflict in the workplace. Due to several changes in economic and demographic trends, to organizations are implementing systems to bolster employee retention and recruitment (Lipsky, Avgar, \& Lamare, 2016). The ICMS is comprised of five components which are compliance, cost, crisis, competition and culture.

The compliance strategy advises organizations to utilize legislation or policy for buy-in when it has been co-developed by stakeholders who will use them (Lynch, 2001). A key ingredient to the successful implementation of the compliance strategy is found in the collaborative design. Several examples as a catalyst for change regarding legislation or policy might include social reform, educational reform, and prison or asylum reform. Because change can be difficult, organizations must continue to include a seat at the decision table when compliance is the catalyst.

An ICMS works on preventing and managing conflict rather than letting it fester and blow-up by encouraging employees with open door policies and organizational wide meetings (Gosline, et al., 2001). The ICMS advocates support for employees by championing leadership for elevation opportunities and institutional awareness on what is important to the employees and their families' such as work-lifebalance. 
The ICMS was created to disrupt the way organizations resolved conflict in the workplace (Lynch, 2001). Organizations could not resolve conflict on an enterprise level because each situation was different, and called for multiple approaches depending upon the involved parties and their perspectives. In other words there was no sustainability, and the ICMS was created to combat the instability by changing the way organizations responded and resolved conflict in the workplace. Leaders began embracing the notion that buy-in was needed by stakeholders using the ICMS (Lynch, 2001). Organizations got smarter, and realized in order to combat low productivity or poor employee morale, healthy work environments had to be created organically by reducing stress, frustration, and mitigated risk overall which affected their bottom line. Executives created crisis or tiger teams to address harassment or negligence by getting ahead of the crisis. Organizations became more competitive by attracting and retaining top talent by implementing flex hours and work-from-home (Lynch, 2001).

Organizations have operated for many years with broken processes and dated methods for resolving conflict in the workplace. Historically, supervisors operated from the power phase where disputes and crisis were resolved by leadership. However, over time employers smartened up and provided rights for employees who wanted to be unionized and provided contract agreements or arbitration (Ury, Brett, \& Goldberg, 1989). This led to long wait times and when a crisis was finally heard, a path towards resolutions was not even agreed upon by all parties.

Much can be said about an ICMS which ultimately incentivizes managers to resolve conflict at the earliest point of acknowledgement by managing and resolving the crisis (Gosline, et al., 2001). Managers now provide solution even when parties cannot agree on the conflict but rather how to resolve the conflict. Employees have a safe haven where their concerns can be heard and respected in a culture where they are likely to grow and feel valued and respected.

The cost strategy recommends organizations experience direct and indirect cost (e.g. loss of employees to stress leave, competitors, early retirement, reduced productivity, frustration, exhaustion, even sabotage) (Lynch, 2001). The strongest organizational factor for driving change is cost; when cost is not managed correctly it can cause greater risk to the bottom line. The ICMS recognizes the conflict and aides' organizations to mitigate the risk and uncertainty which affects overall productivity, employee morale and a healthy work environment.

The crisis strategy assuages crisis when an organization is hit by a single instance of harassment, incompetence, negligence or fraud; managers do not allow a prodromal crisis situation to become an outof-control tsunami (Bell, 2011c; Bell \& Martin, 2019b; Fink, 1986; Lynch, 2001). Whether a single instance or an avalanche of a certain type of dispute, organizations must be intentional regarding crisis. Organizations must provide oversight, investigate, and perform their own due diligence. However, the damage is done, whether internal or external, and is a clear wakeup call for a systematic approach. ICMS can provide prevention and processes to manage the crisis. Conversely, businesses can continue to address each crisis case-by-case which is simply inefficient.

The competition strategy suggests organizations compete to attract and retain the best talent (Lynch, 2001). For organizations to remain relevant and competitive in their industries, a systematic approach is needed to attract and retain the best employees. Companies are now offering flexible hours and skipping the traditional 9-to-5. Employees have options to work from home or remotely, based upon their schedules reducing telecommuting.

The culture strategy proposes organizations spend great time and resources on delivery of their core services but fail to train staff on respecting differences with regards to conflict management (Lynch, 2001). Such examples might include a police force that marginalizes the people it swore to protect or an organization whose mission and vision does not line up with deliverables that support the values of the organization. The culture strategy works when organizations understand that strategy and success go together with conflict resolution and stakeholder's ability to match the organization values and service delivery. 


\section{Case-By-Case Conflict Resolution vs. ICMS}

When using case-by-case to resolve conflict, organizations introduce resolution methods as standalone processes, in three distinct phases: power, rights and interest (Ury, Brett, \& Goldberg, 1989). It was not uncommon for businesses or organizations to approach disputes or conflict in the workplace. If a dispute or conflict was resolved, it was done on a case-by-case basis. Managers can use the power phase to share their expectations and to develop supervisor talent, encourage and provide alternatives for dispute resolution (Ury, Brett, \& Goldberg, 1989). In the power phase, organizations have relied heavily upon management to resolve disputes. Often, employees would refer to the manager in this phase as a dictator. In other words, "my way or the highway," was often an antiquated grievance systems (Katz \& Flynn, 2013).

The rights phase suggests disputes are solved through legislation, employer policy, contracts or agreements (Ury, Brett, \& Goldberg, 1989). Organizations took note that they were not efficient or inconsistent in how they resolved conflict and issues. In the rights phase, this grew over time; dispute resolution emerged in unionized and non-unionized workplaces which led to grievances and arbitration. The interest phase recommends mediation, facilitation, or negotiation for specific disputes (Brubaker, et al, 2014; Ury, Brett, \& Goldberg, 1989). In the interest phase, organizations are experimenting with resolving disputes on a case-by-case basis.

Over time, organizations determined that resolving issues on a case-by-case basis was not efficient and a more formalized process had been adopted. This led to long wait times on resolutions because the crisis could not be agreed upon or even selecting a path for on resolution. Thus, conflict management systems were used only 17 percent in 1997 by 1000 majors corporations, but were up to 30 percent in 2011 (Lipsky, 2015), along with research for more formulaic practices for dispute resolution and best practices (Bingham \& Nabatchi, 2019). Conflict management systems have been shown to correlate positively with organizational outcomes but with no evidence supporting the system effect proposed in the theoretical and prescriptive literature (Roche \& Teague, 2012).

A key difference between ICMS and case-by-case is that ICMS foster features and safeguard environments where managers are expected to prevent, manage, contain and resolve all conflict at the earliest possible time (Gosline, et al., 2001). ICMS equips managers with the necessary skill sets and incentivizes them, thus being held accountable for true leadership. Such skill sets might include the allencompassing, conflict-competent culture and multiple access point strategies.

The all-encompassing strategy is broad in scope, which recommends solutions for multiple problems (Gosline, et al., 2001). This option might include harassment, discrimination, performance reviews, transfers, whistleblowing, and even disciplinary cases. This strategy can be used in a formal setting or non-formal when resolving conflict in the workplace. Even when parties cannot agree on the conflict, the process enables parties to be approachable on how to resolve the conflict.

The conflict-competent culture strategy advocates that people are more likely to grow and thrive in a healthy environment when choice is presented and where they can raise their concerns knowing they will be heard, respected, and acted upon (Gosline, et al., 2001). Conflict is embraced early-on for a lower level conflict resolution because the culture and atmosphere has been created where others feel their concerns are truly heard and not brushed off. Whenever employees feel that they are not being respect or valued, they become disengaged.

The multiple access point strategy suggests subject matter experts who can work in relevant roles and are knowledgeable (Gosline, et al., 2001). This strategy consists of a team leader or knowledge expert who acts as guide to aid individuals within organizations. Often, there are employees that have the resident knowledge within organizations where colleagues would feel more comfortable discussing an issue versus speaking directly with upper management. Having multiple access points throughout an organization helps create a team environment and fosters stronger leadership teams.

The options and choice strategy propose providing individuals rights-based, interest-based, options to solving problems (Gosline, et al., 2001). The options and choice strategy empower users to resolve their own problems by providing a structure through coaching or direct negotiation. But, ICMS enables users on conflict prevention and conflict management, versus the latter, having conflict without any direction 
on resolution. Now users can take advantage of the policies established on fostering greater communications (e.g. open-door policies, organization-wide meetings and specialized skills training).

The support structures strategy advocate organizations support the shift in how conflict is viewed and addressed by providing visible leadership, awareness programs, institutional incentives and mass training (Gosline, et al., 2001). Conflict is embraced because a healthy safe guard system is in place to resolve conflict in the workplace. Employees can tell when organizations care about their growth, they champion leadership training and provide elevation opportunities. Organizations incentivize employees, provide role specific training, host lunch-n-learns, and encourage manager's growth in emotional intelligence.

\section{CONCLUSION}

Overall, we learned that when two or more parties engage in conflict management strategies in the workplace, competition becomes a zero-sum game, and both sides compromise towards an agreeable solution. We discovered that conflict resolution has been a growing issue in the workplace so much that there have been extensive studies to develop strategies to address conflict resolution in the workplace. Several strategies were addressed such as giving in to the opposing sides demands, avoiding conflict indefinitely, collaborating and integrating conflict strategies, compromising to establish an acceptable and/or agreeable solution and of course the zero-sum game.

We exposed several soft skill strategies coupled with the integrated conflict management system comprised of prevention, management, resolution and identifying the key differences between the standalone case-by-case resolution methods. Often, miscommunication can simply be cleared up by clarifying one's intentions, whether verbal or written and understanding one's own emotional intelligence. Instead of being surface and sympathetic, managers can become more empathetic towards conflict understanding employees' needs and helping to provide an effective solution to the underlying problem.

Additionally, we learned that organizations are implementing more effective conflict resolution strategies in the workplace called the integrated conflict management system, or ICMS for short, comprised of a systematic approach to prevention, management, and resolution of conflict. Organizations now have conflict resolution strategies to address compliance by implementing legislation as well as cost strategies geared to mitigate organizational direct and indirect loss due to frustration, exhaustion, stress or even sabotage. Companies are now strategic with crisis management, staving off fierce competition by a single instance or promoting a healthy culture.

Moreover, we discovered that resolving conflict case-by-case is not only ineffective but places an extraordinary amount of pressure on the supervisor by empowering them as the deciding factor in most cases, which leads to animosity, and eventually low employee morale. However, organizations have smartened up and seek a broad scope in providing solutions to multiple problems. When stakeholders are given skin-in-the-game and are valued in the conflict-competent culture, organizations flourish because choice is presented as an option. By providing multiple accesses points as arteries, instead of management silos, employees' perceptions are now interest-based and rights-based. Additionally, the support strategy within organizations now provides visible leadership by promoting career training, continuous education, lunch-n-learns, awareness and institutional programs, and employee incentives.

We also now understand how organizations can address abrasive behavior through the lens of an ICMS versus a case-by-case basis, which leads to low employee morale, lower productivity and even greater absenteeism. Having open dialog about critical and/or crucial issues are vital to organizations and the overall benefits of the team. This strategy helps to effectively address toxic behavior and teach preventive measures to those responsible for managing conflict.

\section{Recommendations}

Companies must investigate the validity of claims. From there an action plan can be implemented as far as resolving the conflict. During the investigation process managers seek to find reasons for the conflict as well as ways to resolve the conflict in a manner that pleases all parties involved. During this time, it is likely for managers to find inefficiencies of processes which most likely cause conflict. When 
organizations are open to learning and implementing new techniques in a systematic approach, they will be able to resolve more conflict in the workplace.

Table 1 shows a detailed description of the three stages of conflict resolution in eight successful steps. To help you remember the eight steps in three stages, use the following memory aid: SIP, DINE, and DANCE. In stage 1, SIP means that you select, identify, and then prepare, like fine wine you SIP. In stage 2, DINE means that you determine and then narrow, like selecting which food you will eat for dinner and then eating that fine dinner. In stage 3, DANCE means that you direct, confirm, and then implement, as what people do after finishing a fine dinner, they dance to celebrate completing the eight steps in three stages. Notice how the memory aid SIP, DINE and DANCE helps you remember the eight verbs associated with the three stages of conflict resolution with little difficulty. Table 1 also shows a brief description of the eight verbs associated with each of the three stages.

TABLE 1

A SUCESSFUL CONFLICT RESOLUTION PROCESS IN 8 STEPS

\begin{tabular}{|c|c|c|c|c|c|c|c|}
\hline \multicolumn{3}{|c|}{ Stage 1: SIP } & \multicolumn{2}{|c|}{ Stage 2: DINE } & \multicolumn{3}{|c|}{ Stage 3: DANCE } \\
\hline Step 1 & Step 2 & Step 3 & Step 4 & Step 5 & Step 6 & Step 7 & Step 8 \\
\hline $\begin{array}{l}\text { Select a } \\
\text { neutral and } \\
\text { suitable } \\
\text { location for } \\
\text { negotiation } \\
\text { s. }\end{array}$ & $\begin{array}{l}\text { Identify } \\
\text { policy } \\
\text { issues for } \\
\text { an agenda } \\
\text { in the } \\
\text { negotiation } \\
\text {; select } \\
\text { negotiators } \\
\text { and the } \\
\text { aspirations } \\
\text { for } \\
\text { individuals, } \\
\text { their } \\
\text { concerns, } \\
\text { and a } \\
\text { protocol } \\
\text { suited for } \\
\text { the types of } \\
\text { issues } \\
\text { covered. }\end{array}$ & $\begin{array}{l}\text { Prepare } \\
\text { preliminary } \\
\text { statement and } \\
\text { limitation. } \\
\text { Determine } \\
\text { communicatio } \\
\text { n levels clearly. } \\
\text { Anticipate } \\
\text { areas for } \\
\text { mutual } \\
\text { understanding, } \\
\text { the nature of } \\
\text { persuasive } \\
\text { arguments, } \\
\text { value of } \\
\text { others' time, } \\
\text { and appreciate } \\
\text { cultural values. }\end{array}$ & $\begin{array}{l}\text { Determine } \\
\text { areas for } \\
\text { deliberation } \\
\text {, potential } \\
\text { solutions of } \\
\text { some issues, } \\
\text { and issue } \\
\text { with no } \\
\text { apparent } \\
\text { agreement. } \\
\text { Establish } \\
\text { bases of } \\
\text { trust, } \\
\text { recognize } \\
\text { risk taking } \\
\text { propensity, } \\
\text { internal } \\
\text { decision- } \\
\text { making } \\
\text { systems and } \\
\text { techniques } \\
\text { for } \\
\text { persuasion. }\end{array}$ & $\begin{array}{l}\text { Narrow } \\
\text { differences to } \\
\text { achieve } \\
\text { consensus; } \\
\text { emphasize } \\
\text { common } \\
\text { interests, and } \\
\text { systematically } \\
\text { search for } \\
\text { alternatives. } \\
\text { Understand } \\
\text { limitations of } \\
\text { all parties. } \\
\text { Use empathy } \\
\text { and conflict } \\
\text { management } \\
\text { techniques. }\end{array}$ & $\begin{array}{l}\text { Direct } \\
\text { final } \\
\text { negotiatio } \\
\text { ns by } \\
\text { facilitating } \\
\text { a give- } \\
\text { and- take } \\
\text { bargaining } \\
\text { process. } \\
\text { Strive for a } \\
\text { win-win } \\
\text { solution. }\end{array}$ & $\begin{array}{l}\text { Confirm } \\
\text { contract } \\
\text { terms based } \\
\text { on the } \\
\text { respective } \\
\text { laws of } \\
\text { countries } \\
\text { involved in } \\
\text { the dispute } \\
\text { resolution, } \\
\text { expectations } \\
\text { for } \\
\text { agreements, } \\
\text { and written } \\
\text { documents. }\end{array}$ & $\begin{array}{l}\text { Implement } \\
\text { the } \\
\text { agreement. } \\
\text { Negotiators } \\
\text { must be } \\
\text { adept at } \\
\text { continuous } \\
\text { observation } \\
\text {, analysis, } \\
\text { and } \\
\text { evaluation; } \\
\text { they must } \\
\text { solve } \\
\text { problems } \\
\text { by adapting } \\
\text { the } \\
\text { negotiation } \\
\text { strategy for } \\
\text { the } \\
\text { negotiation } \\
\text { to be } \\
\text { successful. }\end{array}$ \\
\hline
\end{tabular}

In closing, it is our recommendation that organizations review the risk associated with workplace conflict to determine if an ICMS is needed to add money to the bottom line. We recommend companies integrate a process when they are dealing with workplace conflict resolution. The first step towards resolving conflict resolution is making sure team members on all levels have been trained properly and have the proper tools to deal with conflict. Next, companies should create a standard operating procedure for reporting conflict, whether it is a phone hotline or a direct line to their manager. Once conflict has been reported, it should be investigated for validity. At this point the decision will need to be made if mediation is necessary or if this situation just requires more training on the parts of the people involved in the conflict.

Once the manager has had chance to investigate, a decision must be made as to how to move forward to resolve the conflict. Mediation is always a first resort when trying to resolve conflict, however 
sometime conflict is greater than a mediation process can handle. When the mediation process does not suffice, managers must resort to other methods and techniques for resolving conflict.

While investigation and mediation are ways to handle conflict once it arrives, having a training program for team members in place could help to mitigate conflict before it arises. It is our recommendation that companies implement training for all team members that involves conflict resolution, and is updated and refreshed annually. Having a training program in place reduces the cost of conflict for companies by having trained team members. Lastly, having the proper leadership in place also helps to mitigate and reduce conflict. A strong, trained, leadership team will be well equipped to resolve conflict. The leadership team will have the proper tips and techniques in its tool box to resolve conflict with little or no effect on the company. It is important for companies to identify leaders that are able to lead the transformation change within an organization.

\section{Additional Resources}

While Fey (2018) advocates 12 techniques to resolve workplace conflict, Tankersley (2016) has created a very interesting game where there are 6 ways to end conflict [See https://www.vitallearning.com/blog/office-conflict-resolution-games]. Bill Howatt developed a survey in 2015 that companies can use to help identify the potential losses in dollar amounts by employee positions, when workplace conflicts are not resolved quickly and efficiently. The results vary based on employee salary. The survey can be found at: https://www.howatthronline.com/conflict/

\section{REFERENCES}

Ahmed, Z., Shields, F., White, R., \& Wilbert, J. (2010). Managerial communication: the link between frontline leadership and organizational performance. Journal of Organizational Culture, Communications and Conflict, 14(1), 107-120.

Aula, P., \& Siira, K. (2010). Organizational communication and conflict management systems. Nordicom Review, 31(1), 125-141.

Baughman, P., Williams, L., Oatis, T., \& Bell, R.L. (2007). Effective managerial communications for the technical core. International Journal of Business and Public Administration, 4(1), 1-16.

Beckwith, L. (2016). Common causes of conflict. [Video] Retrieved from https://www.sagu.edu/thoughthub/causes-of-conflict

Bell, R. L. (2010a). A three step process to save troubled employees from themselves. Supervision, 71(11), 3-6.

Bell, R. L. (2010b). Getting the most from your frontline workers: A rule of thumb for observing and rewarding good behavior. Supervision, 71(10), 9-12.

Bell, R. L. (2011a). Addressing employees' feelings of inequity: Capitalizing on equity theory in modern management. Supervision, 72(5), 3-6.

Bell, R. L. (2011b). Reminding managers to motivate and communicate: A primer on the basic operations in the work of the manager. Supervision, 72(8), 7-10.

Bell, R. L. (2011c). Managing the prodromal crisis situation: Two techniques to avoid turning a surge into a mega-tsunami. Supervision, 72(2), 3-6.

Bell, R. L. (2012). Three facets for communicating managerial trustworthy behavior. Supervision, 73(11), 16-20.

Bell, R. L. (2013). Removing the source of conflict from conflict situations. Supervision, 74(11), 3-6.

Bell, R. L., \& Bodie, N. D. (2012). Delegation, authority and responsibility: Removing the rhetorical obstructions in the way of an old paradigm. Journal of Leadership, Accountability and Ethics, 9(2), 94-108.

Bell, R. L., \& Martin, J. S. (2008). The promise of managerial communication as a field of research. International Journal of Business and Public Administration, 5(2), 125-142. 
Bell, R. L., \& Martin, J. S. (2012). The relevance of scientific management and equity theory in everyday managerial communication situations. Journal of Management Policy and Practice, 13(3), 106115.

Bell, R. L., \& Martin, J. S. (2014). Managerial communication. USA: Business Expert Press, LL.C.

Bell, R. L., \& Martin, J. S. (2019a). Managerial communication for organizational development. USA: Business Expert Press, LL.C.

Bell, R. L., \& Martin, J. S. (2019b). Managerial communication for professional development. USA: Business Expert Press, LL.C.

Bell, R. L., Sutanto, W., Baldwin, R., \& Holloway, R. (2014). The gender inequity misconception: how Texas female business school faculty are smashing the glass ceiling. Journal of Management Policy and Practice, 15(1), 39-57.

Bingham, L. B., \& Nabatchi, T. (2019). Dispute system design in organizations. In Handbook of Conflict Management (pp. 121-144). USA: Routledge.

Branch, S., Ramsay, S., Sheehan, M., \& Barker, M. (2004). Us and them: Understanding upwards bullying through the lens of social identity theory. Griffith University Research Online. Retrieved from https://pdfs.semanticscholar.org/89cf/63bfdf7914417385389c7157f9cbcb29bc2f.pdf.

Brubaker, D., Noble, C., Fincher, R., Park, S. K. Y., \& Press, S. (2014). Conflict resolution in the workplace: What will the future bring? Conflict Resolution Quarterly, 31(4), 357-386.

Cloutier, O., Felusiak, L., Hill, C., \& Pemberton-Jones, E. J. (2015). The importance of developing strategies for employee retention. Journal of Leadership, Accountability \& Ethics, 12(2), 119 129.

Conbere, J. P. (2001). Theory building for conflict management system design. Conflict Resolution Quarterly, 19(2), 215-236.

Corkindale, G. (2007). How to manage conflict. Harvard Business Review. Retrieved from https://hbr.org/2007/11/how-to-manage-conflict.

Crawshaw, L. (2010). Coaching abrasive leaders: Using action research to reduce suffering and increase productivity in organizations. International Journal of Coaching in Organizations, 8(1), 60-77.

Dontigney, E. (2018). 5 Conflict management strategies. Hearst Newspapers, LLC. Retrieved from https://smallbusiness.chron.com/5-conflict-management-strategies-16131.html

Doyle, A. (2018). Conflict management skills lists and examples. The Balance Careers. Retrieved from https://www.thebalancecareers.com/conflict-management-skills-2059687.

Fey, J. (2018). 12 Techniques for resolving conflicts in the workplace. Digital Project Manager.

Fink, S. (1986). Crisis management: Planning for the inevitable, AMA Membership Edition. USA: AMACOM.

Fox, S., \& Stallworth, L. E. (2009). Building a framework for two internal organizational approaches to resolving and preventing workplace bullying: Alternative dispute resolution and training. Consulting Psychology Journal: Practice and Research, 61(3), 220-241.

Fulk, K.H., Bell, R.L., \& Bodie, N.D. (2011). Team management by objectives: Enhancing developing teams' performance. Journal of Management Policy and Practice, 12(3), 17-26.

Fuller, K. (2017). How to recognize toxic individuals and toxic relationships. Psychology Today. Retrieved from https://www.psychologytoday.com/us/blog/happiness-is-state-mind/201708/howrecognize-toxic-individuals-and-toxic-relationships.

Glambek, M., Anders, S., \& Einarsen, S. (2018). Workplace bullying, the development of job insecurity and the role of laissez-faire leadership: A two-wave moderated mediation study. Work \& Stress, 32(3), 297-312. Retrieved from https://www.tandfonline.com/doi/full/10.1080/02678373.2018.1427815.

Goleman, D. (2006). Working with emotional intelligence. New York, NY: Bantam Dell.

Gosline, A., \& Thomas, A., et al. (2001). Designing integrated conflict management systems: guidelines for practitioners and decision makers in organizations. Cornell Studies in Conflict and Dispute Resolution, 4. Retrieved from http://digitalcommons.ilr.cornell.edu/icrpubs/2/ 
Harper, J. (2012). 10 Tips for tackling the toughest workplace conflicts. U.S. News: Money. Retrieved from https://money.usnews.com/money/careers/articles/2012/07/18/10-tips-for-tackling-thetoughest-workplace-conflicts

Howatt, B. (2015). The long-term costs of not resolving workplace conflicts. The Globe and Mail Leadership Lab. Retrieved from https://www.theglobeandmail.com/report-onbusiness/careers/leadership-lab/the-long-term-costs-of-not-resolving-workplaceconflicts/article25527147/.

Katz, N. H., \& Flynn, L. T. (2013). Understanding conflict management systems and strategies in the workplace: A pilot study. Conflict Resolution Quarterly, 30(4), 393-410.

Knight, R. (2015). How to handle difficult conversations at work. Harvard Business Review. Retrieved from https://hbr.org/2015/01/how-to-handle-difficult-conversations-at-work.

Lawler, J. (2010). The real cost of workplace conflict. Entrepreneur. Retrieved from https://www.entrepreneur.com/article/207196.

Liberman, E., Levy, Y. F., \& Segal, P. (2009). Designing an internal organizational system for conflict management: Based on a needs assessment. Dispute Resolution Journal, 64(2), 62-74.

Lipsky, D. B. (2015). The future of conflict management systems. Conflict Resolution Quarterly, 33(S1), S27-S34.

Lipsky, D. B., Avgar, A. C., \& Lamare, J. R. (2016). The evolution of conflict management policies in US corporations: From reactive to strategic. In Reframing Resolution (pp. 291-313). London: Palgrave Macmillan.

Lynch, J. (2003). Integrated conflict management programs emerge as an organization development strategy. Alternatives to the High Cost of Litigation, 21(5), 99-113.

Lynch, J. F. (2001). Beyond ADR: A systems approach to conflict management Negotiation Journal, 17(3), 206-216. Retrieved from https://onlinelibrary.wiley.com/doi/abs/10.1111/j.15719979.2001.tb00237.x.

Moore, C. (1986). The Mediation Process: Practical strategies for resolving conflict. New York: Wiley \& Sons.

Nguyen, T., White, S., Hall, K., Bell, R. L., \& Ballentine, W. (2019). Emotional intelligence and managerial communication. American Journal of Management, 19(2), 54-63.

Overton, A., \& Lowry, A. (2013). Conflict management: Difficult conversations with difficult people. Clinics in Colon and Rectal Surgery, 26(4), 259-264. Retrieved from https://www.ncbi.nlm.nih.gov/pmc/articles/PMC3835442/ and https://thedigitalprojectmanager.com/12-conflict-resolution-techniques-workplace/.

Roche, W., \& Teague, P. (2012). Do conflict management systems matter? Human resource management, 51(2), 231-258.

Roebuck, D. B., Bell, R. L., \& Hanscom, M. E. (2016). Differences in the observed frequency distributions of male and female feedback behaviors. Journal of Applied Management \& Entrepreneurship, 21(2), 6-25.

Roebuck, D. B., Bell, R. L., Raina, R., \& (Catherine) Lee, C. E. (2015). The effects of home country, gender, and position on listening behaviors. Journal of Organizational Culture, Communications and Conflict, 19(2), 93-120.

Roebuck, D. B., Bell, R. L., Raina, R., \& Lee, C. E. (2016). Comparing perceived listening behavior differences between managers and nonmanagers living in the United States, India, and Malaysia. International Journal of Business Communication, 53(4), 485-518.

Shane-Joyce, M. P., \& Bell, R. L. (2010). Communication practices of managers and the predictability of uncivil communication in response. International Journal of Business and Public Administration, $7(2), 37-51$.

Shonk, K. (2015). What is conflict resolution, and how does it work? Program on Negotiation: Harvard Law School. Retrieved from https://www.pon.harvard.edu/daily/conflict-resolution/what-isconflict-resolution-and-how-does-it-work/.

136 Journal of Leadership, Accountability and Ethics Vol. 16(4) 2019 
Shonk, K. (2018). 5 Conflict resolution strategies. Program on Negotiation: Harvard Law School. Retrieved from https://www.pon.harvard.edu/daily/conflict-resolution/conflict-resolutionstrategies/.

Stone, D., Patton, B., \& Heen, S. (2010). Difficult Conversations-How to discuss what matters most. New York: Penguin Books.

Tankersley, J. (2016). Conflict resolution games: 6 ways to end conflict in your office. Retrieved from https://www.vital-learning.com/blog/office-conflict-resolution-games.

Thibeaux, S., Tillotson, G., Falls, T., \& Bell, R. L. (2006). The imposition of diversity: The imposition of diversity training through top down management communication. Journal of Diversity Management, 1(2), 1-12.

Thomas, R. (2002). Conflict management systems: A methodology for addressing cost of conflict in the workplace. Mediate, RIS. Retrieved from https://www.mediate.com/articles/thomasR.com

Tillett, G., \& French, B. (1991). Resolving conflict: A practical approach $3^{\text {rd }}$. Ed. Oxford: Oxford University Press.

Ury, W., Brett, J., \& Goldberg, S. (1988). Getting disputes resolved: Designing systems to cut the cost of conflict. San Francisco: Jossey-Bass. 